\title{
CONSTRUCTION MANAGEMENT TOOLS USING 3D-CAD, VIRTUAL REALITY, RFID, AND PHOTOGRAPHY TECHNOLOGIES
}

\author{
Naruo Kano, Dr.Eng \\ Professor, Department of Architecture \\ Waseda University \\ 3-4-1 Okubo,Shinjuku, Tokyo, JAPAN 169-8555 \\ kano@waseda.jp
}

\begin{abstract}
Since the development of the PERT/CPM method in 1958, many planning and controlling tools have been developed; however, no method has exceeded the PERT/CPM to make an epoch-making impact on the methodology for planning and controlling at a construction site. The advanced technologies are strongly expected to serve as platforms for the development of new planning and controlling tools. 3D-CAD, Virtual Reality and RFID technologies with conventional photography technology are expected to be key technologies to change the way of planning and controlling. This paper discusses the significance of these four technologies in construction management. Through the case studies carried out at Waseda University, the author pursues the feasibility of new tools for construction management.
\end{abstract}

Keywords: 3D-CAD, Virtual Reality, RFID, photography, construction management, planning and controlling

\section{INTRODUCTION}

In recent years, attention has been focused on 3D-CAD and VR as technologies for planning and controlling tools at construction sites.[1]-[9] Historically, 3D-CAD first appeared in the building design phase in the 1980's. However, as computers to be used for 3D-CAD were too expensive and architectural CAD software did not have sufficient functions in practice, the use of 3D-CAD was limited to designing large-scale buildings and special-purpose buildings such as high-rise buildings and nuclear power plants.

At present, with the evolution of computer and software technologies, 3D-CAD is able to be fully installed on personal computers, not only at the engineering department of head offices but also at site offices.

In this paper, the author paper discusses the significance of 3D-CAD and VR technologies used for planning and controlling in the construction phase, and refers to the roles of RFID technology and conventional photography technology. Through the case studies carried out at Waseda University, the author pursues the feasibility of implementation of these technologies in the construction phase.

\section{A MODEL OF A CONSTRUCTION SITE}

\subsection{Four Viewpoints in Planning and Controlling}

Conventionally, the concept of 'activity' has been used to represent the progress of work at a construction site, using bars in a bar-chart and arrows/nodes in a network diagram. The resource allocation method has been used to connect the activities with associated resources, namely, objects, such as workers, materials, components, temporary scaffoldings, and construction machines.
For many years, the major focus of planning and controlling has been set on activities not on objects. However, by obtaining a technology to grasp a three-dimensional space, visible objects at a site would be able to be the targets in planning and controlling. When we observe an activity, what we actually observe are objects associated with the activity. For example, when we observe workers moving with a specific purpose, we recognize such a scene as an activity. We should realize that the essential focus of planning and controlling in construction is not on activities but on the objects which are engaged in the activities.

When we observe some situation at a construction site, we would observe visual objects then identify the geometrical relationships of the objects comprehensively. A situation is represented by a scene of specific spatial area at a specific time. In planning and controlling at a construction site, visual objects would be identified from the following viewpoints:

(1) To identify an individual visual object as a substance

(2) To identify a set of visual objects as an activity

(3) To identify a set of visual objects as a situation

Each object is given a name respectively. We put a name to each object and distinguish one from the other. We regard some objects collectively as a set, and put a name to each set as a set object. For example, a curtain wall consists of a window frame and a glass; and an external wall unit consists of a curtain wall and an air conditioning unit. These components can be defined as a component breakdown structure. In this case, an external wall unit refers to a set object consisting of three objects. Therefore, microscopically, an external wall unit can be recognized as three objects; however, macroscopically, it can be recognized as one set object. 


\subsection{Substance, Activity, Situation, and World}

Substance represents the physical presence of an individual visual object. As shown in Figure.1, 'Activity' represents a motion and/or action of 'Substance' in a time series; and 'Situation' represents a situational set of Substances in a specific space. Also, 'World' represents a set of Substances changing dynamically identified both in a time series and in a space. 'Situation' is produced as a result of 'Activity', then will be a condition to start another 'Activity'.

Thus, 'World' represents the whole motion and relation changing both in time and space, rather than a content of each element.

It is necessary to identify the actual situation at a construction site from the above-mentioned four aspects, namely, 'Substance', 'Activity', 'Situation', and 'World'.

Table 1 shows the models for a construction plan corresponding to each element, as well as the tools for monitoring the progress of work. As shown in Table 1, the models representing a plan for each object are Database, Network Model, Perspective CG image, and Virtual Reality. In order to monitor each object, RFID Tag, Photo image, Bar Chart/Network Diagram, and human's visual impression can be used respectively as tools.

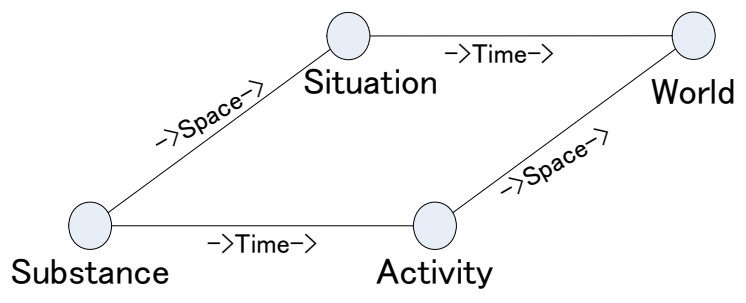

Figure 1 Relations among Substance, Activity, Situation, and World

Table 1 Models and Tools for Objects

\begin{tabular}{|l|l|l|l|}
\hline Objects & Axis & $\begin{array}{l}\text { Models for } \\
\text { Planning }\end{array}$ & $\begin{array}{l}\text { Tools for } \\
\text { Monitoring }\end{array}$ \\
\hline Substance & Non & $\begin{array}{l}\text { Object } \\
\text { Database }\end{array}$ & RFID Tag \\
\hline Activity & Time & Network Model & $\begin{array}{l}\text { BarChart/ } \\
\text { Network } \\
\text { Diagram }\end{array}$ \\
\hline Situation & Space & $\begin{array}{l}\text { Perspective CG } \\
\text { Image }\end{array}$ & Photo Image \\
\hline World & $\begin{array}{l}\text { Time/ } \\
\text { Space }\end{array}$ & Virtual Reality & $\begin{array}{l}\text { Visual } \\
\text { Impression }\end{array}$ \\
\hline
\end{tabular}

2.3 Planning and Controlling by Focusing on Visual Objects

Due to an enormous amount and type of visual objects existing at a construction site, we have not had a technology to represent each object for managers to facilitate their understanding, planning, and controlling of construction process. In order to handle objects at the site, managers should be able to identify each object with visible features, spatial geometrical locations, relationships with adjacent other objects as well as its properties.

Using 3D-CAD and VR technologies, we can visually identify objects which are scattered around a construction site and rebuild the objects on a computer as digital information.

Besides 3D-CAD and VR technologies, two other technologies would play important roles to facilitate managers to identify an enormous amount of objects and situations at construction sites. These two technologies are RFID and conventional photography technology.

RFID technology provides us with information on each object existing in a real world through a tag attached to each object (Figure 2). Photography technology provides us with a tool for recording and identifying situations through images, which have its 3D geometrical data on camera positions and angles (Figure 3). A photo image provides a virtual scene with information on the real situation of a site at a specific time, and makes it possible to compare the photo image and the image generated by the perspective method on the virtual scene, thereby contributing discerning the difference between the images.
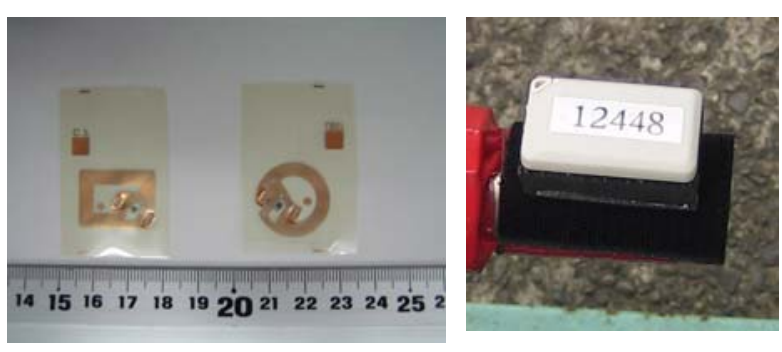

(a) Passive-type RFID tag (b) Active-type RFID tag Figure 2 RFID system

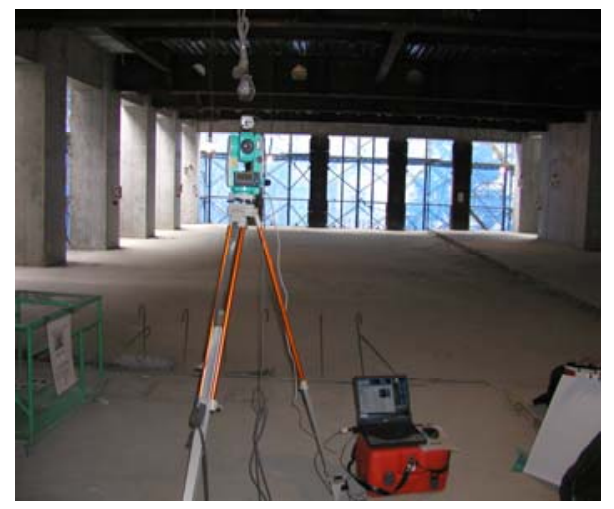

Figure 3 CCD camera mounted on non-prism total-station for taking photo images with $3 \mathrm{D}$ geometrical data

\section{A PROTOTYPE SYSTEM - VIRTUAL CONSTRUCTION SITE SYSTEM}

VCS System, Virtual Construction Site System, is a prototype system to create a virtual environment for a construction site on a computer to enable us to plan and control the construction site through exploring the virtual scenes representing a construction site. 
VCS System is applied to rehearse the building construction performance on a computer in advance of the actual construction work, so we are able to find out problems and have an opportunity to improve them in advance. Moreover, after the start of actual construction, as the records on the progress of work are input into VCS System one after another, the real-time progress at a construction site could be reproduced on a computer. Therefore, even at a site office in a remote place, we would be able to observe the progress of work in VCS System.

VSC System has six sub-systems:

(1) 3D-CAD System (MicroStation)

(2) Virtual Scene Generating System (WorldUp ActiceX)

(3) Data Handling System (Visual Basic)

(4) Computer Graphic System (3D MAX)

(5) Planning and Controlling System (Visual Basic)

(6) Application Systems

(ex. MS-Project, Excel, Visio, et al)

Figure 4 shows the scheme of VCS system. The core is Data Handling System which handles data in collaboration with other sub-systems. 3D-CAD system sends the 3D data of building components to Virtual Scene Generating System through the transformation of CAD file.

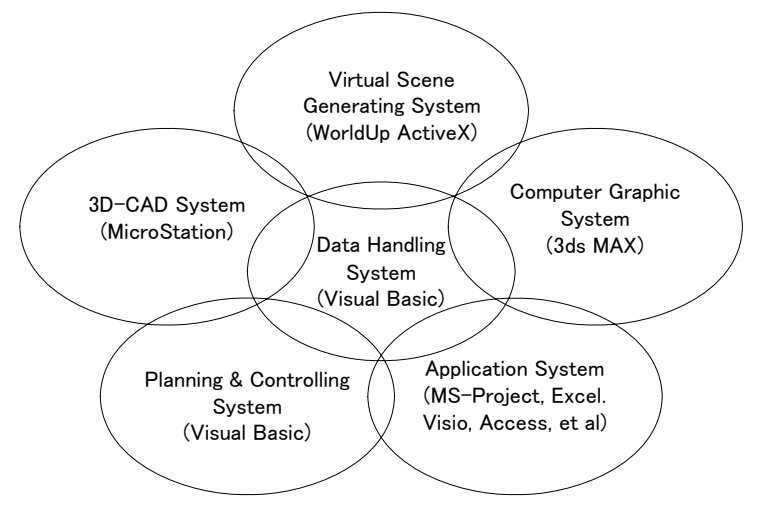

Figure 4 VSC System

\section{New Management Tools}

4.1. 3DCAD for Modeling Substances in 3D Space

To focus on each visual object in planning and controlling, information on a building to be built should be represented using an individual part and component placed in a three-dimensional space. 3D-CAD technology provides us with useful tools to digitize the size, feature, and position of the object.

Using 3D-CAD in the building design phase, a building is broken down into parts and components, which have three dimensional data on the features, location, and direction to be assembled. These data include useful information for making a plan in this construction phase. One of the well-known advantages is a benefit for quantity surveying. Three dimensional data provide the quantity, length, area, and volume of each component: a column, floor, and window, and help managers to get precisely the total quantities. These data also enable managers to estimate not only the quantities of components, but also the cost and duration of the project precisely.

Three dimensional and geometrical data from 3D-CAD provide much more detailed information for managers to produce appropriate construction plans for the specific building design in the same way that a site manager makes plans by exploring the drawings of the building.

Figure 5 shows 3D-CAD data on a building. Information on three-dimensional models of components will serve as fundamental and inevitable information for planning and controlling in construction.

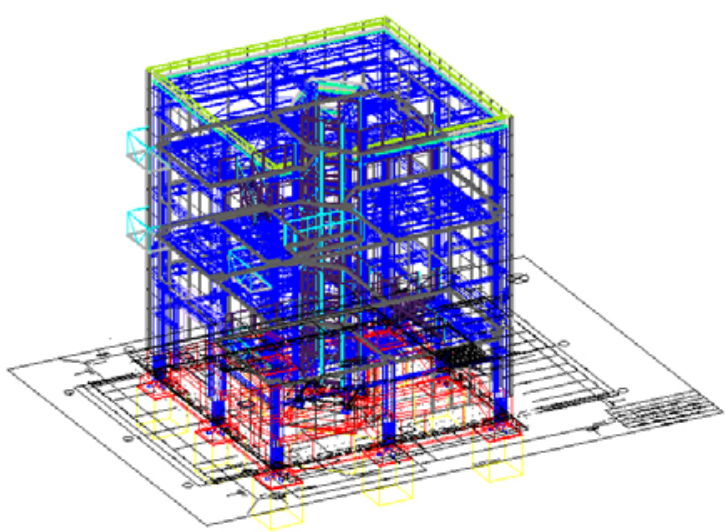

Figure 5 Broken-down components in 3D-CAD system

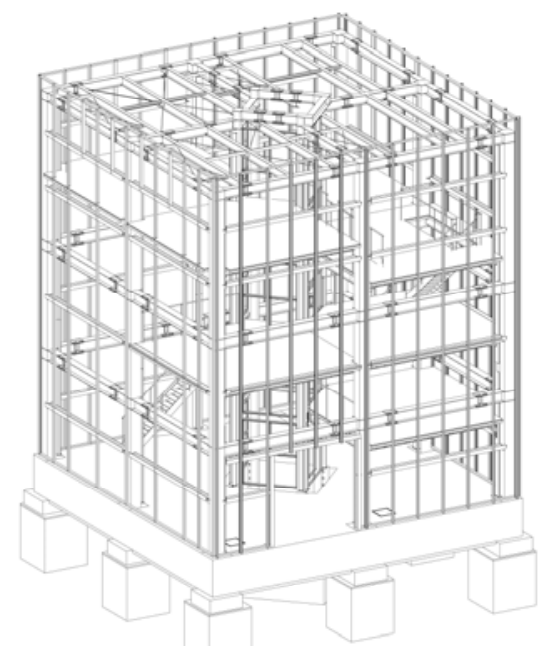

Figure 6 Structural components in 3D-CAD system

\subsection{Virtual Reality for Modeling Situations}

\subsubsection{Utilization of Virtual Environment}

At a construction site, it is essential to confirm the details of a building to be built, and examine how components should be assembled in the right position and direction according to the drawings.

In order to examine parts and components to be installed in a three-dimensional space, it is necessary to walk around the site and look around the spatial area as if we were at the real site, obtain information on components, and confirm 
whether space-conflict does not exist among components. Moreover, it is necessary to jump instantaneously to another specific area to investigate a specific component.

For virtual reality with a focus on a visual aspect, Real-Time Walk-Through technology plays an important role. Using this technology in construction planning and controlling, managers can walk around the virtual construction site to visually consider various situations of the site prior to the start of the actual work.

\subsubsection{Real-Time Walk-Through}

A manager can obtain the site situations on a specific date precisely by walking around a virtual construction site using Real-Time Walk-Through technology. This technology is suitable for observing components and construction machines allocated in a three-dimensional space.

Real-Time Walk-Through technology can be utilized in construction planning, as a manager can visually confirm the situations of the construction site, such as the layout of scaffoldings and construction machines, as if he/she were at the real site. During the construction, a manager can observe the site situations through the virtual world at a site office, without spending time and effort for walking around a spacious site.

Figure 7 and Figure 8 show Real-Time Walk-Through around the vicinity of a site. Here, the scenes of forthcoming situations at a site are presented, and by looking at the site from the neighborhood, managers can confirm the situations of each area and explore the safety and city landscape.

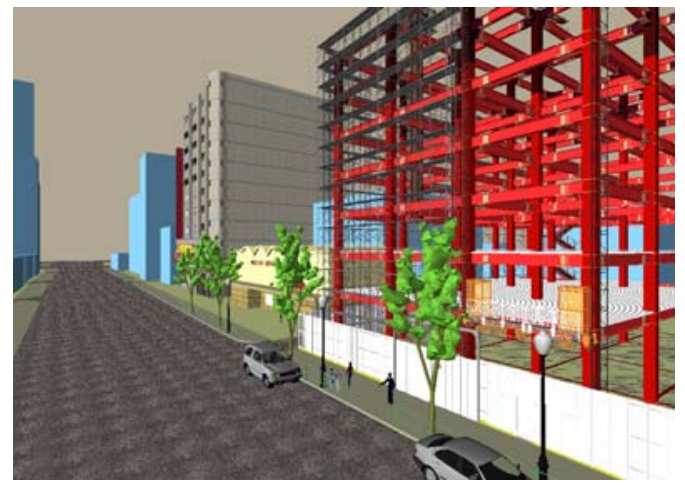

Figure 7 Real-Time Walk-Through around a site

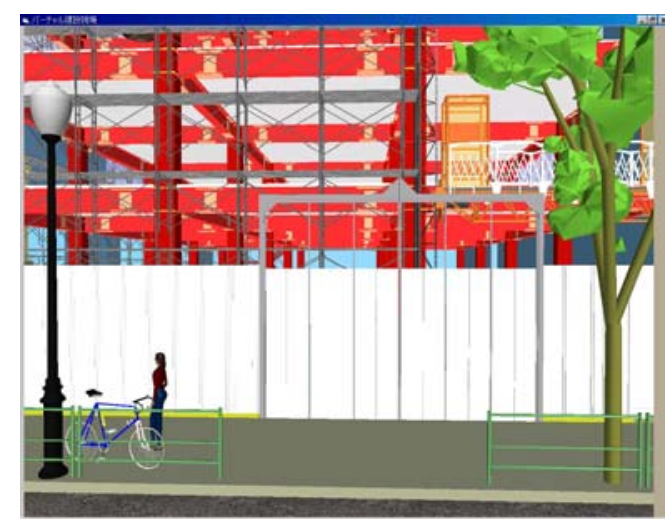

Figure 8 Real-Time Walk-Through at the gate of a site

4.3. RFID Tags for Monitoring Substances and Activities 4.3.1. Utilization of RFID Tags

RFID tags attached to objects at a construction site make it possible to access the information attached to tags without contact. Using this technology, real-time information on all objects existing at a site can be obtained easily through readers installed at gates and lifts as well as those carried by workers and site managers.

Using RFID technology, it becomes possible to record on an enormous amount of building components individually during a construction period, and to individually control components scattered around a construction site. At current construction sites, only the major components, such as workers, materials, components, scaffoldings, and construction machines, have been identified in planning and controlling. However, using RFID tags, the whole objects existing at a site could be figured out accurately at a real time in the site office.

\subsubsection{Identification of Substances using RFID Tags}

RFID tags make it possible to monitor the presence and/or motion of each substance at a construction site. As shown in Figure 9, the monitoring on substances at a construction site covers transportation works from a factory/stockyard, installation works, and carrying-out wastes generated by activities to a waste disposal facility. When using scaffoldings, they should be moved to another work area where another activity needs scaffoldings.

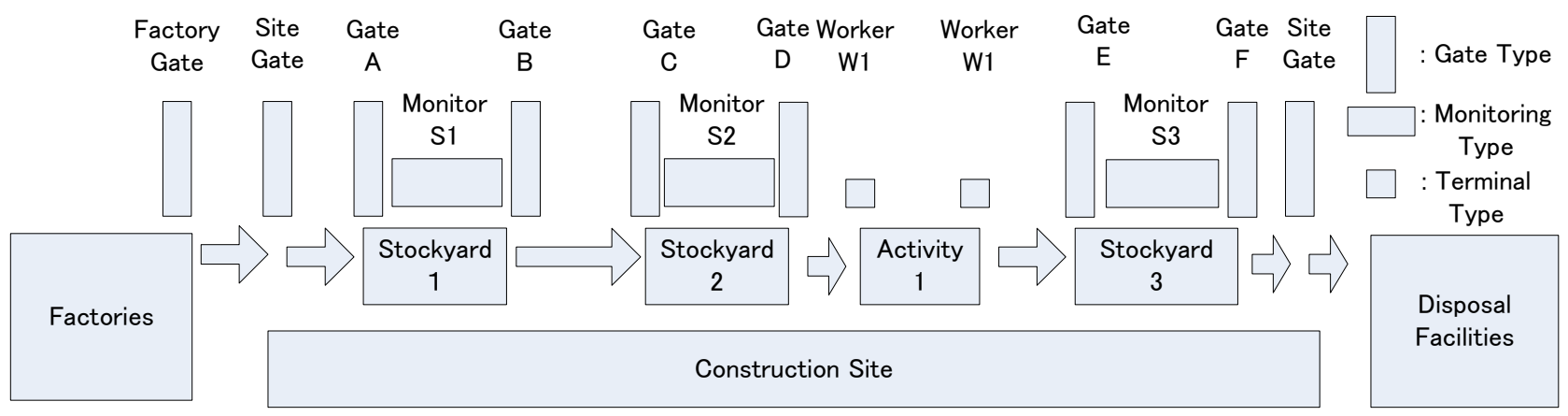

Figure 9 Types of RFID Readers Used at a Construction Site 
The following three methods are used for identifying RFID tags attached to substances at a construction site.

(1) Gate Type: An RFID reader is set at a gate to identify RFID tags when passing through a gate

(2) Monitoring Type: An RFID reader is covering a certain area to identify RFID tags at regular intervals (3 sec, $10 \mathrm{sec}, 30 \mathrm{sec}, 1 \mathrm{~min}, 3 \mathrm{~min}, 10 \mathrm{~min} . .$. )

(3) Terminal Type: A portable RFID reader is carried by a worker to identify RFID tags.

\subsubsection{RFID tags used at a construction site}

Various tags are required for construction management at a site as shown below.

(1) Component Tag: Attached to each component to represent its attributes

(2) Material Tag: Attached to each material to be cut and/or processed to represent its attribute

(3) Package Tag: Attached to a package of components and materials to represent attributes of components and materials contained in a package

(4) Equipment Tag: Attached to construction machines and temporary scaffoldings to represent these attributes

(5) Human Tag: To represent attributes of workers and managers

(6) Activity Tag: Attached to each component finished as a result of work to represent its attributes

(7) Management Tag: To represent attributes of management activities, such as process control and quality control of finished components

(8) Space Tag: Attached to floors, walls, and components to represent the three-dimensional positions at a site as well as attributes of the space

\subsubsection{Scenario for using RFID tags}

Conventionally, the progress of work has been managed using information about start and finish event of work. In construction management using RFID tags, the progress of work can be managed through the management of conditions of each substance using RFID tags.

Transportation and storage of components at a site can be managed by obtaining information on RFID tags through Gate Type and/or Monitor Type readers installed at respective place at a site. During the installation work phase, workers can read RFID tags from a portable terminal type reader and obtain information about components related to the work.

The roles of RFID tags and related information during the work at a site are assumed to be as shown below:

(1) At the start of work, to read RFID tags of workers engaged in a work and send the following information to a server at the site office.
[1] Activity ID
[2] Working crew ID
[3] Worker ID
[4] Workspace ID

(2) To read RFID tags of a component to be used in a work, and to confirm that there are all the required components, and send the information to a server that the condition of starting a work are fulfilled.
[1] Activity ID
[2] Component ID

(3) To read RFID tags of a component to be installed at the time of the installation, and to read an RFID tag (Space Tag) attached to the position where each component is installed, and then send the information to a server on which position each member has been installed.

[1] Working crew ID

[2] Responsible person ID

[3] Component ID

[4] Installation position ID

(4) To attach RFID tags (Activity Tag) showing the work record as required, and send the information to a server.

[1] Activity ID

[2] Working crew ID

[3] Attached Activity tag ID

[4] Component ID

(5) At the end of work, to send the information about the finish of work to a server when the work is finished.

[1] Activity ID

[2] Working crew ID

[3] Work finish time

Figure 10 shows tags attached to packages of glass components and sash components. The position of tags attached to the packages at a factory or at the time of shipping is saved in the server. Therefore, a worker can easily confirm the position of tags by accessing a virtual construction site. Figure 11 shows the situation of more than one tag attached to window components. As shown in the figure, three tags are attached to one window, namely, a component tag holding the attributes of a glass, a component tag holding the attributes of a sash, and an activity tag holding the record of an installation work.

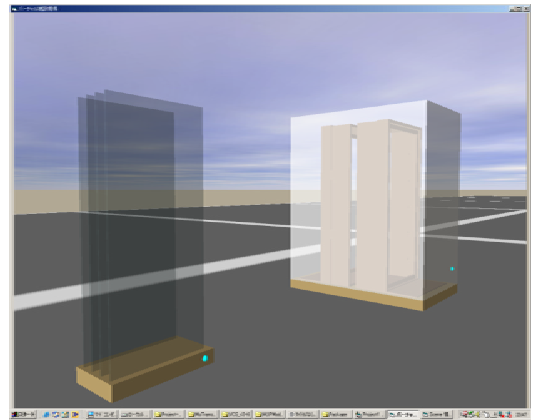

Figure 10 Tags attached to glass and sash packages

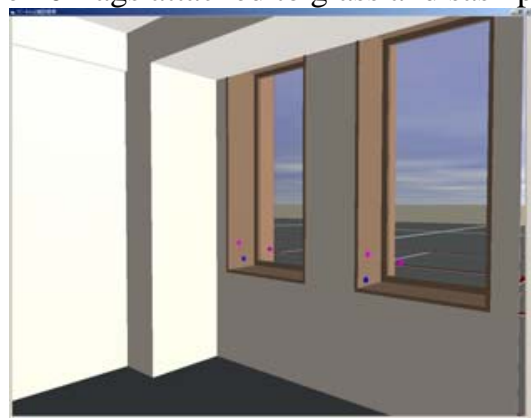

Figure 11 Tags attached to a sash 


\subsection{Photo Images for Monitoring Situations}

\subsubsection{Utilization of Photo Images}

Situations at a construction site cannot be fully represented only by collecting alpha-numerical information on each object at the site. In order to represent a situation, it is necessary to collect the geometrical relationships of each object with other objects as well as the object itself which comprises the situation.

This study suggests the use of photo images is suitable to depict situations at a site. Photo images have been used to record various situations at construction sites. Situations are identified as an aggregate of objects existing in a specific space. The CG image, which is produced by using the perspective method on the virtual scene from the same viewpoint as the camera, shows the precisely the similar image as a photo image taken at the site.

Therefore, by comparing a VR image and a photo image, it becomes possible to identify the differences in the scene of situation between to-be-built and as-built.

\subsubsection{Identification of Situations Using Photo Images}

Figure 12 shows a photo image and a VR image of a work-area situation after the concrete work. The comparison of these two images clarifies that there is a difference in the height of a floor on the left side. In the photo image, a wood is placed on the floor; however, in the VR image obtained from the design drawings, there is a bump on the concrete floor. By comparing a photo and a VR image, we can visually inspect differences between as-build and to-be-built in each part.
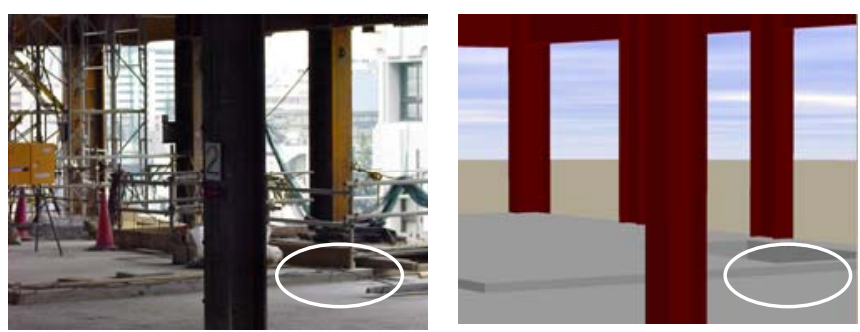

Figure 12 Difference between a photo image and a VR image regarding a level of concrete floor

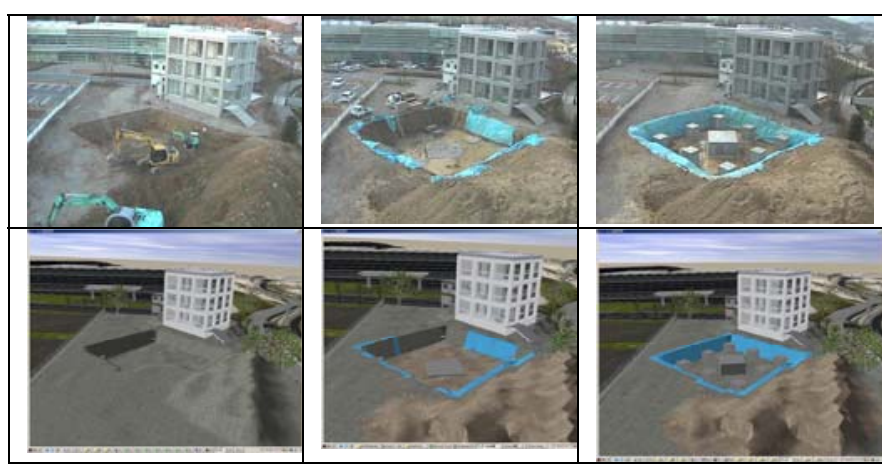

Figure 13 A photo Image and a VR Image of the ongoing construction
Figure 13 shows a photo image and a VR image of the ongoing construction. Using a camera installed at a fixed point, the progress in construction was recorded as a series of photo images. Each photo image taken at a site and the corresponding VR image produced on the schedule provide site managers with a clear view of the degree of progress by detecting differences between two images.

\section{CONCLUSION}

Introduction of 3D-CAD technology into the building construction phase will bring a revolutionary change to the tools of planning and controlling. Consequently, the methodology of planning and controlling will be changed from the conventional one with a focus on activities to the one with a focus on individual object associated with activity, such as workers, components, scaffoldings, and construction machines.

VR technology enables a manager to identify a large amount of visual objects. RFID technology provides us with a tool to obtain real-time information on a large amount of objects at a construction site. Though these three technologies have been developed separately, the integration of these three with a conventional photography technology will create new tools for construction management.

\section{REFERENCES}

[1] Retik, A., "Planning and monitoring of construction projects using virtual reality”, International Journal of Project Management, Vol. 3, pp. 28-31, 1997.

[2] McKinney, K., and Fischer, M., "Generating, evaluation, and visualizing construction schedules with CAD tools”, Automation in Construction 7, pp. 443-447, 1998.

[3] Akinci, B., and Fischer, M. "Time-space conflict analysis based on 4D production models”, Conf. On Computing in Civil Engineering, ASCE, Reston, Va., pp. 342-353, 1998.

[4] Retik, A., and Shapira, A., "VR-based planning of construction site activities”, Automation in Construction 8, pp. 671-680, 1999.

[5] Whyte, J., Bouchlaghem, N., Thorpe, A., and McCaffer, R., "From $\mathrm{CAD}$ to virtual reality: modelling approaches, data exchange and interactive 3D building design tools”, Automation in Construction 10, pp. 43-55, 2000.

[6] Koo, B., and Fischer, M., "Feasibility study of 4D CAD in commercial construction”, Journal of Construction Engineering and Management, July/August, pp. 251-260, 2000.

[7] Kamat, V. R., and Martinez, J. C., "Visualizing simulated construction operations in 3D”, Journal of Computing in Civil Engineering, October, pp. 329-337, 2001.

[8] Jaafari, A., Manivong, K.K., and Chaaya, M., "VIRCON: Interactive system for teaching construction management”, Journal of Construction Engineering and Management, January/February, pp. 66-75, 2001.

[9] Kano, N., Yao, T, Hosoda, M, "Virtual Construction Site: Development of a Prototype System and the Issues", Proc. of Symposium on Kenchiku Seisan, pp.57-62, Architectual Institute of Japan, 2001. (in Japanese) 